\title{
以原位形成的磷酸铝骨架为模板制备纳米孔炭
}

\author{
张 敏 ${ }^{1}$, 朱万春 ${ }^{1}$, 刘 钢 ${ }^{1, \mathrm{a}}$, 张秀艳 ${ }^{1}$, 祖艳红 ${ }^{1}$, 张文祥 ${ }^{1}$, 间文付 ${ }^{2}$, 贾明君 ${ }^{1, \mathrm{~b}}$ \\ ${ }^{1}$ 吉林大学化学学院理论化学计算国家重点实验室, 吉林长春 130021 \\ 2 吉林大学化学学院无机合成与制备国家重点实验室, 吉林长春 130012
}

\begin{abstract}
摘要: 以不同有机物 (邻苯二酚、间苯二酚、对苯二酚、乙二醇、环己胺) 为辅助炭源, 通过直接炭化含柠檬酸及磷酸铝的复合 物制备了一系列纳米孔炭材料 (NC), 采用多种表征手段研究了辅助炭源对最终炭材料性质的影响. 结果表明, NC 材料的结构 和表面官能团性质随辅助炭源的变化而改变, 其中以间苯二酚、对苯二酚、环己胺为辅助炭源制备的炭材料在空气氧化苯甲醇 反应中表现有较高的催化活性.

关键词: 纳米孔炭; 磷酸铝; 表面官能团; 苯甲醇; 空气氧化

中图分类号: 0643 文献标识码: A

收稿日期: 2011-09-28. 接受日期: 2011-11-15.

a通讯联系人. 电话: (0431)85155390; 传真: (0431)88499140; 电子信箱 lgang@jlu.edu.cn

b通讯联系人。电话: (0431)85155390; 传真: (0431)88499140; 电子信箱: jiamj@jlu.edu.cn

基金来源：吉林省科学与技术发展计划 (201105009); 高等学校博士点基金新教师项目 (20090061120024); 国家自然科学基金 (21003059).

本文的英文电子版(国际版)由Elsevier出版社在ScienceDirect上出版(http://www.sciencedirect.com/science/journal/18722067).
\end{abstract}

\section{Preparation of Nanoporous Carbon Using an Aluminophosphate Framework Template}

\author{
ZHANG Min ${ }^{1}$, ZHU Wanchun ${ }^{1}$, LIU Gang ${ }^{1, a}$, ZHANG Xiuyan ${ }^{1}$, ZU Yanhong ${ }^{1}$, ZHANG Wenxiang ${ }^{1}$, \\ YAN Wenfu' ${ }^{2}$, JIA Mingjun ${ }^{1, b}$ \\ ${ }^{1}$ State Key Laboratory of Theoretical and Computational Chemistry, College of Chemistry, Jilin University, \\ Changchun 130021, Jilin, China \\ ${ }^{2}$ State Key Laboratory of Inorganic Synthesis and Preparative Chemistry, College of Chemistry, Jilin University, \\ Changchun 130012, Jilin, China
}

\begin{abstract}
Different organic compounds, $o$-dihydroxybenzene, $m$-dihydroxybenzene, $p$-dihydroxybenzene, glycol, and cyclohexylamine, were used as the extra carbon source for a series of nanoporous carbon (NC) materials prepared by directly carbonizing composites containing citric acid and aluminum phosphate. The effect of the extra carbon source was studied. The structure and surface functional groups on the NC material were different with different extra carbon sources. The NC materials prepared using $m$-dihydroxybenzene, $p$-dihydroxybenzene or cyclohexylamine have excellent catalytic activity for the aerobic oxidation of benzyl alcohol to benzaldehyde.

Key words: nanoporous carbon; aluminophosphate; surface functional group; benzyl alcohol; aerobic oxidation

Received 28 September 2011. Accepted 15 November 2011.

${ }^{a}$ Corresponding author. Tel: +86-431-85155390; Fax: +86-431-88499140; E-mail: lgang@jlu.edu.cn

${ }^{b}$ Corresponding author. Tel: +86-431-85155390; Fax: +86-431-88499140; E-mail: jiamj@jlu.edu.cn

This work was supported by the Development Project of Science and Technology of Jilin Province (201105009), the Specialized Research Fund for the Doctoral Program of Higher Education (20090061120024), and the National Natural Science Foundation of China (21003059).

English edition available online at Elsevier ScienceDirect (http://www.sciencedirect.com/science/journal/18722067).
\end{abstract}


Porous carbons are important materials widely used in adsorption, separation, storage, electrochemistry, and catalysis [1-5]. Much attention has been paid to the design and development of novel porous carbon materials with different structures and surface properties for special technical requirements. In the field of catalysis, the abundant surface functional groups on the carbon materials can be used either as active sites or as anchoring sites for active centers to give high catalytic activity [6,7]. The pore size and specific surface area of the carbon materials are also key parameters that influence the dispersion states of active species and catalytic properties of carbon-based catalysts [8].

The structure and surface chemistry of carbon materials are dependent on many factors, such as preparation method, carbon sources, carbonization conditions, and post-treatment [9]. Many compounds, including sugar, alcohols, resin, polysaccharose, and aromatic compounds, have been used as the carbon sources for the preparation of various porous carbon materials [10-18]. Bleda-Martinez et al. [15] reported that porous carbon materials with different pore structures were produced from different carbon precursors (anthracite and carbon fibers) by different activation methods. Titirici et al. [16] found clear structural and morphological differences in carbons prepared from different carbon sources (pentoses and hexoses) under hydrothermal conditions. Yuan and co-workers [17] synthesized monolithic carbon materials with resorcinol/formaldehyde resol as the carbon precursor and found that the molar ratio of formaldehyde to resorcinol had a significant influence on the structure of the carbon materials. Lenghaus et al. [18] used different phenolic resins as carbon precursors and successfully changed the pore parameters of the carbon materials obtained. The carbon sources or precursors have significant effects on the structure and surface properties of the resulting carbon materials.

Previously, our group reported a sol-gel route to synthesize nanoporous carbon denoted as NC with microporous and/or mesoporous characteristics. The mesoporous aluminum phosphate that was formed in situ during carbonation acted as the template, and citric acid and sucrose were the carbon sources [19]. The resulting NC had abundant surface oxygen-containing functional groups, and can be directly used as the active catalyst for the aerobic oxidation of benzyl alcohol [20], and as the catalyst support for highly dispersed solid base catalysts [21,22].

The goal of this work is to further tune the structure and surface properties of the NC material to give higher catalytic activity in aerobic oxidation. Several organic compounds, including $o$-dihydroxybenzene, $m$-dihydro-xybenzene, $p$-dihydroxybenzene, glycol and cyclohexylamine, were separately used as the substitute of sucrose to prepare
NC materials. $\mathrm{N}_{2}$ adsorption, Raman spectroscopy, Fourier transform infrared (FT-IR) spectroscopy, Boehm titration, $\mathrm{X}$-ray photoelectron spectroscopy (XPS), and temperature-programmed desorption (TPD) were used to study the effect of the extra carbon sources on the structure and surface chemistry of the NC material. The catalytic performance of these carbon materials was investigated with the aerobic oxidation of benzyl alcohol.

\section{Experimental}

\subsection{Synthesis of NC materials}

The NC materials were prepared using a procedure described previously [19]. Phosphoric acid (85\%, $8.7 \mathrm{ml})$ was dropped into a $200 \mathrm{ml}$ aqueous solution containing $48 \mathrm{~g}$ aluminium nitrate nonahydrate, $13.5 \mathrm{~g}$ citric acid (CA) and the extra carbon source (28.2 g o-dihydroxybenzene, $28.2 \mathrm{~g}$ m-dihydroxybenzene, $28.2 \mathrm{~g} p$-dihydroxybenzene, $47.7 \mathrm{~g}$ glycol or $25.4 \mathrm{~g}$ cyclohexylamine). A diluted aqueous ammonia (10 wt\%) solution was used to adjust the $\mathrm{pH}$ value of the solution to 5.0. The mixture was heated at $353 \mathrm{~K}$ in the open air to give the solid precursor. The precursor was first pretreated at $573 \mathrm{~K}$ in a muffle furnace for a few minutes, then calcined at $1073 \mathrm{~K}$ under argon for $6 \mathrm{~h}$. Finally, the composite was marinated in $4 \mathrm{~mol} / \mathrm{L} \mathrm{HNO}_{3}$ at $323 \mathrm{~K}$ and stirred for some hours to remove the aluminophosphate (AlPO) component. The resulting product was filtered, washed with deionized water, and dried at $373 \mathrm{~K}$ overnight.

The porous carbon materials obtained by different extra carbon sources, $o$-dihydroxybenzene, $m$-dihydroxybenzene, p-dihydroxybenzene, glycol or cyclohexylamine, were denoted as NC-a, NC-b, NC-c, NC-d, and NC-e, respectively (Table 1). A reference sample (NC-ref) with sucrose as the extra carbon source was also prepared using a literature procedure [19].

\subsection{Characterization}

$\mathrm{N}_{2}$ adsorption-desorption isotherms at $77 \mathrm{~K}$ were obtained on a Micromeritics ASAP 2010N analyzer. Prior to the measurement, the sample was degassed at $523 \mathrm{~K}$ for $8 \mathrm{~h}$. Specific surface areas were calculated using the BET (Brunauer Emmett Teller) model. The pore volumes were calculated from the amount of nitrogen adsorbed at the relative pressure of $0.94\left(p / p_{0}\right)$. Pore size distribution was evaluated from the desorption branch of the nitrogen isotherms using the BJH (Barrett Joyner Halenda) model. Raman spectra were obtained with a Renishaw Model 1000 Raman spectrometer. FT-IR measurement was conducted on a Thermo Nicolet 6700 FT-IR spectrometer. The FT-IR spectrum of each sample was averaged from 32 scans. The 
Boehm titration method [23] was used to determine the amounts of surface groups. NC sample $(0.1 \mathrm{~g})$ was placed in $10 \mathrm{ml}$ of $0.05 \mathrm{~mol} / \mathrm{L}$ solution of the following: sodium hydroxide, sodium carbonate, sodium bicarbonate, and hydrochloric acid. The vials were sealed and shaken for $24 \mathrm{~h}$ and filtrated, and then a known quantity of hydrochloric acid was added to each filtrate. The excess acid left in the solution was titrated with $\mathrm{NaOH}$. The amounts of acidic sites of various types were calculated with the assumption that $\mathrm{NaOH}$ neutralizes carboxylic, phenolic, and lactonic groups, $\mathrm{NaHCO}_{3}$ neutralizes only carboxylic groups, and $\mathrm{Na}_{2} \mathrm{CO}_{3}$ neutralizes carboxylic and lactonic groups. The number of surface basic sites was calculated from the amount of hydrochloric acid that reacted with the NC material. XPS experiments were carried out on a Thermo ESCA LAB 250 system with $\mathrm{Mg} K_{\alpha}$ source (1254.6 eV). TPD experiments were carried out with an online mass spectrometer (Balzers OmniStar). A typical procedure was as follows. A carbon sample was placed between quartz wool in a quartz tube, heated in Ar to $353 \mathrm{~K}$ and kept at that temperature for $0.5 \mathrm{~h}$. Then it was heated to $1073 \mathrm{~K}$ with a ramp rate of $5 \mathrm{~K} / \mathrm{min}$. The outlet gas was diverted to an online mass spectrometer (Balzers OmniStar) for analysis. The concentrations of CO and $\mathrm{CO}_{2}$ were determined by the intensities of $\mathrm{m} / \mathrm{z}$ at 28 and 44 , respectively.

\subsection{Catalytic activity tests}

The aerobic oxidation of benzyl alcohol was carried out to evaluate the catalytic activity of the NC materials (a-e). The reaction was carried out in a $50 \mathrm{ml}$ two-neck flask at atmospheric pressure. NC (0.3 g) was used as catalyst, which was suspended in $10 \mathrm{ml}$ toluene by stirring. Then 1.0 mmol benzyl alcohol was added into the reactor. The mixture was contacted with air and the reaction temperature was kept at $353 \mathrm{~K}$. A gas chromatograph equipped with a capillary column was used to analyze the products.

\section{Results and discussion}

\subsection{Characterization of NC materials}

$\mathrm{N}_{2}$ adsorption-desorption isotherms of the samples are shown in Fig. 1. Samples NC-a and NC-d exhibited Type I isotherms indicating the microporous characteristics of these materials. The nitrogen adsorption-desorption isotherm of NC-b was a Type IV curve with a H2 hysteresis loop at relative pressures $0.4-0.7$, indicating that NC-b was a mesoporous material with ink bottle-type pores [24]. Samples NC-c and NC-e displayed Type I plus IV isotherms with a small hysteresis loop, which indicated the presence of both micropores and mesopores in these materials [25].
Table 1 summarizes the BET surface areas, pore volumes, and average pore diameters of the NC samples. NC-a showed the lowest BET surface area and pore volume, while those of NC-b were the largest. These results showed that the use of different extra carbon sources in the sol-gel system gave significant changes in the textural parameters of the porous carbon.

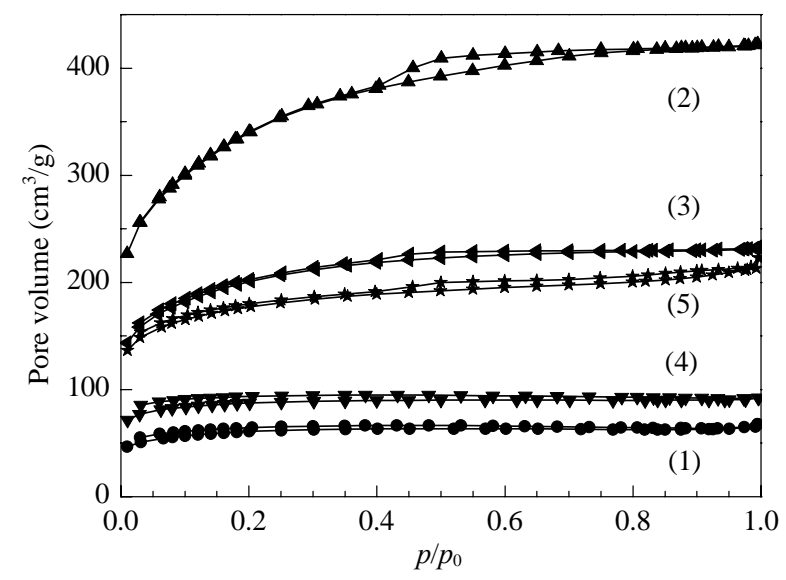

Fig. 1. $\mathrm{N}_{2}$ adsorption-desorption isotherms of NC materials prepared with different extra carbon sources. (1) NC-a; (2) NC-b; (3) NC-c; (4) NC-d; (5) NC-e.

Table 1 Synthesis parameters and textural properties of the NC materials

\begin{tabular}{lcrcc}
\hline Sample & Carbon source & $\begin{array}{c}A_{\mathrm{BET}} / \\
\left(\mathrm{m}^{2} / \mathrm{g}\right)\end{array}$ & $\begin{array}{c}\text { Pore volume } \\
\left(\mathrm{cm}^{3} / \mathrm{g}\right)\end{array}$ & $\begin{array}{c}\text { Pore size } \\
(\mathrm{nm})\end{array}$ \\
\hline NC-a & $o$-dihydroxybenzene & 212 & 0.10 & 2.0 \\
NC-b & $m$-dihydroxybenzene & 1182 & 0.65 & 2.2 \\
NC-c & $p$-dihydroxybenzene & 698 & 0.36 & 2.1 \\
NC-d & glycol & 304 & 0.14 & 1.9 \\
NC-e & cyclohexylamine & 615 & 0.33 & 2.1 \\
\hline
\end{tabular}

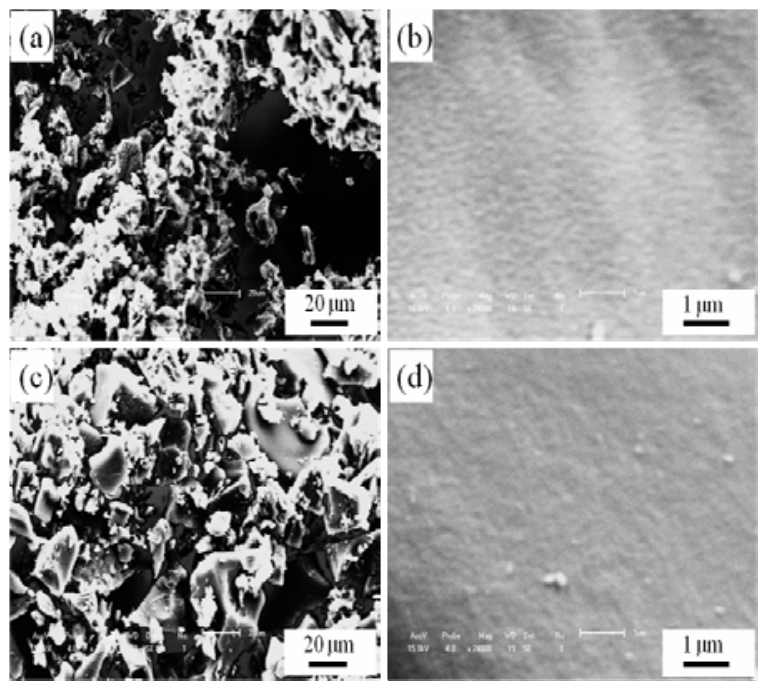

Fig. 2. SEM images of the NC materials. (a) and (b) NC-a; (c) and (d) NC-b. 
Figure 2 shows the SEM images of NC-a and NC-b. At relatively high magnification, the morphology of these carbon materials was a quite uniform film-like shape, indicating that the carbon was present as a rigid continuous phase rather than as an isolated phase in these NC materials [26]. The XRD patterns of the NC samples are shown in Fig. 3. All of them exhibited a broad diffraction peak centered at $26^{\circ}$ and a weak peak centered at $44^{\circ}$, which were, respectively, assigned to diffraction from the (002) and (100) planes of graphite [27]. The broad signals indicated that the graphitic level of the NC materials was relatively low [19].

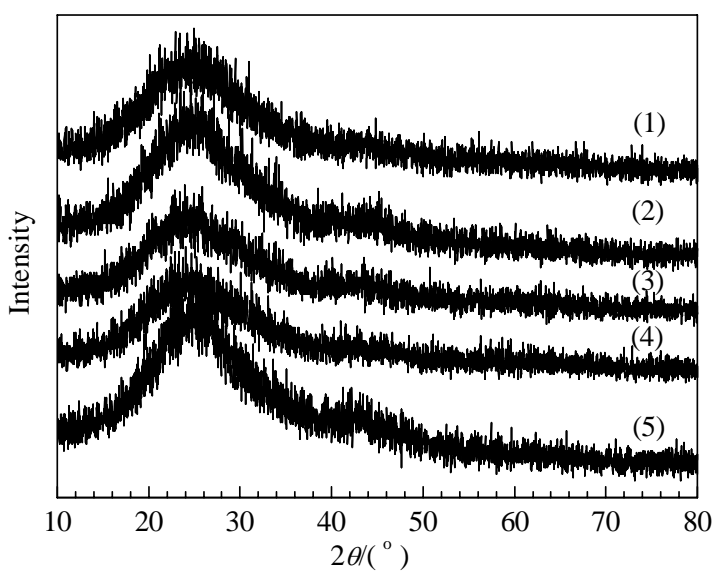

Fig. 3. XRD patterns of NC materials prepared with different extra carbon sources. (1) NC-a; (2) NC-b; (3) NC-c; (4) NC-d; (5) NC-e.

Figure 4 shows the Raman spectra of the NC materials. All the samples exhibited two peaks at 1350 (D band) and $1590 \mathrm{~cm}^{-1}$ (G band), indicating the presence of the graphitic phase in these materials [28]. The relatively low intensity and broad signal of the $G$ band were evidence that the graphitic level of these carbon materials was not very high [29], in agreement with the XRD patterns.

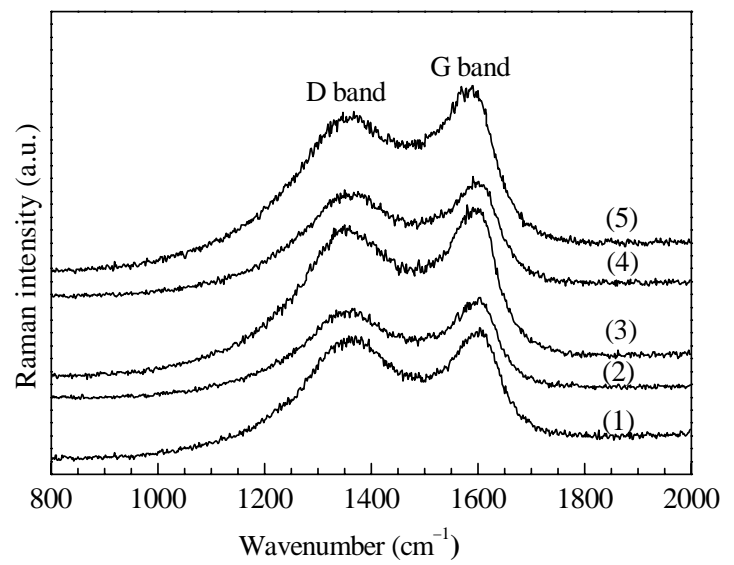

Fig. 4. Raman spectra of the NC materials prepared with different extra carbon sources. (1) NC-a; (2) NC-b; (3) NC-c; (4) NC-d; (5) NC-e.
Figure 5 shows the FT-IR spectra of the NC samples. There were three main peaks in the $1000-3500 \mathrm{~cm}^{-1}$ region for all the samples. The bands at 1250 and $1100 \mathrm{~cm}^{-1}$ corresponded to the stretching modes of the $\mathrm{C}-\mathrm{O}$ moieties in ethers, acids and esters. The bands in the $1500-1750 \mathrm{~cm}^{-1}$ range were ascribed to the $\mathrm{C}=\mathrm{O}$ stretching vibration of different groups. The broad band centered at $3400 \mathrm{~cm}^{-1}$ can be attributed to the $-\mathrm{OH}$ stretch [30,31]. These results showed that several kinds of oxygen-containing functional groups were present on the surface of the NC materials.

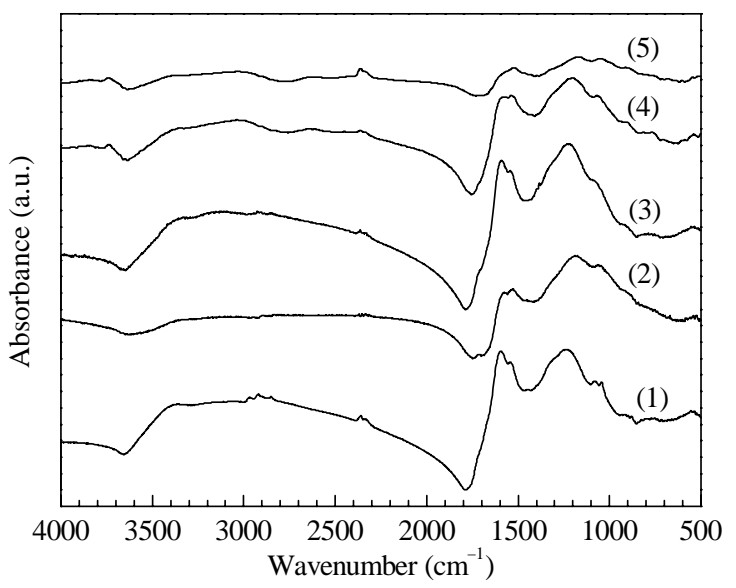

Fig. 5. FT-IR spectra of NC samples prepared with different extra carbon sources. (1) NC-a; (2) NC-b; (3) NC-c; (4) NC-d; (5) NC-e.

Table 2 shows the Boehm titration results of various NC materials. Both acidic groups and basic groups were present on the surface of the NC materials. NC-a possessed the largest amount of acidic groups, including carboxylic, lactonic, and phenolic groups, while NC-d had the lowest amount of acidic groups. The amounts of basic groups in NC-a, NC-b, and NC-d were much higher than in NC-c and NC-e. The results showed that changing the extra carbon source also influenced the acidic and basic characteristics of the NC materials.

Table 2 Results from the Boehm Titration

\begin{tabular}{lcccccc}
\hline \multirow{2}{*}{ Sample } & \multirow{2}{*}{$\mathrm{pH}$} & \multicolumn{5}{c}{ Content (mmol/g) } \\
\cline { 3 - 7 } & & Carboxylic & Lactonic & Phenolic & Acidic & Basic \\
\hline NC-a & 3.72 & 1.15 & 1.07 & 2.69 & 4.91 & 4.50 \\
NC-b & 4.13 & 1.30 & 1.04 & 1.07 & 3.41 & 4.03 \\
NC-c & 3.94 & 1.58 & 0.93 & 1.55 & 4.06 & 2.35 \\
NC-d & 5.01 & 1.05 & 0.15 & 0.43 & 1.63 & 4.92 \\
NC-e & 4.01 & 1.10 & 1.63 & 1.68 & 4.41 & 1.95 \\
\hline
\end{tabular}

The XPS spectra of the samples showed a strong C $1 s$ peak at $284.5 \mathrm{eV}$ due to graphitic carbon and a significant $\mathrm{O}$ $1 s$ peak at $530 \mathrm{eV}$ (not shown here). In addition, a weak $\mathrm{N}$ $1 s$ peak at $400 \mathrm{eV}$ was found. Table 3 shows the percentage amounts of these elements on the surface of the NC materials. It can be seen clearly that the surface elemental compo- 
sition of these NC materials was different when different extra carbon sources were used for the synthesis of the carbon materials.

Table 3 Percentage amounts of C, O, and N on the surface of the NC materials

\begin{tabular}{lcccc}
\hline \multirow{2}{*}{ Sample } & \multicolumn{3}{c}{ Component content (\%) } & \multirow{2}{*}{ O/C } \\
\cline { 2 - 4 } & $\mathrm{C}$ & $\mathrm{O}$ & $\mathrm{N}$ & \\
\hline NC-a & 76.5 & 13.8 & 8.8 & 0.18 \\
NC-b & 82.2 & 10.4 & 6.6 & 0.13 \\
NC-c & 81.5 & 11.3 & 6.7 & 0.14 \\
NC-d & 78.4 & 14.1 & 6.8 & 0.18 \\
NC-e & 79.5 & 13.6 & 6.0 & 0.17 \\
\hline
\end{tabular}

Figure 6 shows the $\mathrm{C} 1 s$, O $1 s$, and $\mathrm{N} 1 s$ XPS spectra of NC-e (a representative sample). According to the literature $[20,32,33]$, the deconvoluted four peaks of the C 1 s spectra were: peak 1 (284.6 eV), graphitized carbon; peak 2 (286.0-286.3 eV), carbon in phenolic, alcohol, ether or $\mathrm{C}=\mathrm{N}$ groups; peak 3 (287.3-287.6 eV), carbon in carbonyl or quinone groups; peak 4 (288.8-289.1 eV), carbon in carboxyl or ester groups. Similarly, the deconvoluted four peaks of the $\mathrm{O} 1 \mathrm{~s}$ spectra were: peak 1 (531.0-531.9 eV), carbonyl oxygen of quinones; peak 2 (532.3-532.8 eV), carbonyl oxygen atoms in ester, anhydrides, and oxygen atoms in hydroxyl groups; peak 3 (533.1-533.8 eV), noncarbonyl (ether-type) oxygen atoms in esters and anhydrides; peak 4 (534.3-535.4 eV), oxygen atoms in carboxyl groups. The $\mathrm{C}=\mathrm{O}$ (e.g. quinone, carbonyl) group was one of the main groups in the above NC materials. The deconvoluted four peaks of the $\mathrm{N} 1 s$ spectra were [34,35]: peak 1 (398.7 \pm $0.3 \mathrm{eV})$, pyridinic- $\mathrm{N}(\mathrm{N}-6)$; peak $2(400.3 \pm 0.3 \mathrm{eV})$, pyrrolic-N (N-5); peak $3(401.4 \pm 0.5 \mathrm{eV})$, quaternary-N (N-Q); peak 4 (402-405 eV), forms of oxidized nitrogen $(\mathrm{N}-\mathrm{X})$, which indicated that several nitrogen-containing groups were also present on the surface of the NC materials.

Table 4 summarizes the relative concentration of the functional groups in the $\mathrm{C} 1 s, \mathrm{O} 1 s$, and $\mathrm{N} 1 s$ XPS spectra of the NC materials. The C $1 s$ spectra showed that all the materials mainly comprised graphitized carbon together with some oxygen-containing groups. NC-b and NC-c had slightly higher concentration of the graphitized carbon and lower concentration of oxygen-containing groups in comparison with NC-a, NC-d and NC-e. The O $1 s$ spectra showed that most oxygen atoms were from different carbonyl oxygen groups and hydroxyl groups (peak 2). The quinone group was another major oxygen functional group. $\mathrm{NC}$-a material had the highest concentration of quinone group of the NC materials. NC-b and NC-c also had high contents of the quinone group, which were higher than those of NC-d and NC-e. The N $1 s$ spectra indicated the relative concentration of different kinds of nitrogen-containing groups, which were also different with different carbon sources. Since there was no nitrogen in the carbon precursors (except cyclohexylamine), the nitrogen in the NC materials was from nitrogen-containing reagents such as aluminum nitrate and aqueous ammonia. These nitrogen-containing reagents probably reacted with the carbon precursor during the carbonization process to form different nitrogen-containing groups, including pyridinic-N, pyr-
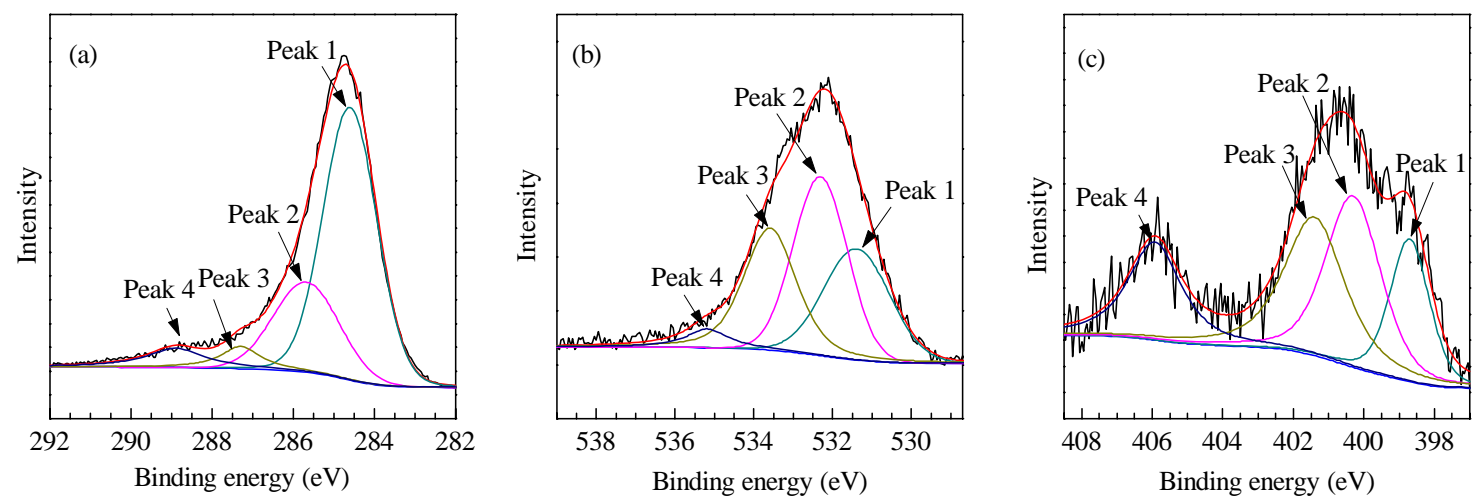

Fig. 6. C $1 s(\mathrm{a}), \mathrm{O} 1 s$ (b), and N $1 s$ (c) XPS spectra of NC-e prepared from cyclohexylamine.

Table 4 Relative concentration of functional groups in the C $1 s, \mathrm{O} 1 s$, and N $1 s$ XPS spectra

\begin{tabular}{|c|c|c|c|c|c|c|c|c|c|c|c|c|}
\hline \multirow{2}{*}{ Sample } & \multicolumn{4}{|c|}{ C $1 s(\%)$} & \multicolumn{4}{|c|}{$\mathrm{O} 1 s(\%)$} & \multicolumn{4}{|c|}{$\mathrm{N} 1 s(\%)$} \\
\hline & Peak 1 & Peak 2 & Peak 3 & Peak 4 & Peak 1 & Peak 2 & Peak 3 & Peak 4 & Peak 1 & Peak2 & Peak 3 & Peak 4 \\
\hline NC-a & 60.4 & 27.9 & 6.6 & 5.1 & 38.0 & 41.8 & 16.1 & 4.1 & 24.4 & 38.7 & 24.0 & 12.9 \\
\hline NC-b & 70.4 & 22.5 & 4.5 & 3.0 & 34.0 & 36.7 & 24.7 & 4.6 & 15.3 & 30.9 & 35.5 & 18.3 \\
\hline NC-c & 74.5 & 18.1 & 4.1 & 3.3 & 34.1 & 40.0 & 21.4 & 4.5 & 26.1 & 31.8 & 28.5 & 13.6 \\
\hline NC-d & 60.1 & 28.1 & 7.5 & 4.3 & 30.0 & 40.8 & 24.9 & 4.3 & 21.5 & 35.0 & 23.4 & 20.1 \\
\hline NC-e & 62.8 & 24.7 & 5.5 & 7.0 & 30.7 & 36.7 & 27.3 & 5.3 & 18.0 & 31.3 & 30.7 & 20.0 \\
\hline
\end{tabular}


rolic-N, quaternary- $\mathrm{N}$, and oxidized nitrogen groups.

The TPD profiles of the NC samples are shown in Fig. 7. The scale of the ordinate in Fig. 7(a) and 7(b) is the same. According to the literature [36-38], the evolution of $\mathrm{CO}_{2}$ at low temperature $(<673 \mathrm{~K})$ can be assigned to the decomposition of the carboxylic functional group, while the contribution at high temperature was attributed to the decomposition of carboxylic anhydride and lactone groups. In the CO evolution, a peak was observed from all the samples in the higher temperature range ( $>873 \mathrm{~K}$ ) due to the decomposition of the carbonyl, quinone, and ether groups. In addition, a weak CO peak at lower temperatures $(<673 \mathrm{~K})$ was assigned to the decomposition of the ketone and aldehyde groups and carboxylic anhydrides. In combination with the above XPS result, it can be concluded that the CO peak above $673 \mathrm{~K}$ was due to the decomposition of quinone and carbonyl groups. Concerning the relative intensity of the desorption peaks, NC-a has the largest amount of quinone groups, while NC-b and NC-c also have relatively large amounts of quinone groups, which were slightly larger than those of NC-d and NC-e. These results confirmed further that different kinds of oxygen-containing functional groups were present in the NC materials, and their contents depended on the carbon source.
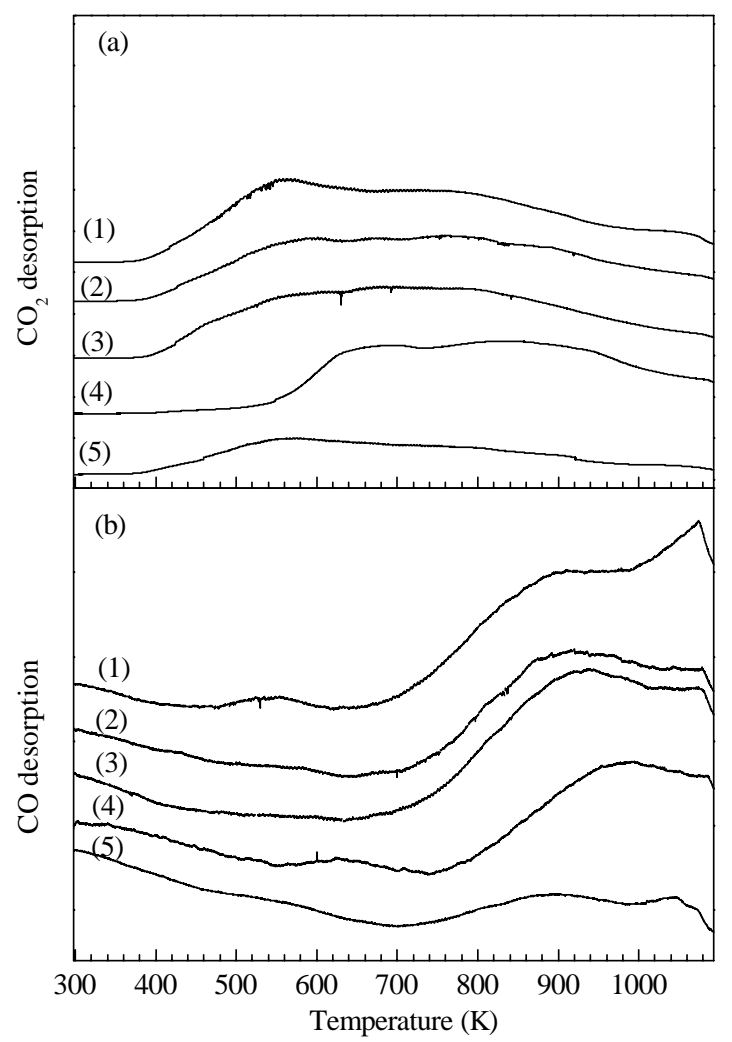

Fig. 7. Comparison of the TPD profiles of $\mathrm{NC}$ materials for $\mathrm{CO}_{2}$ desorption (a) and CO desorption (b). (1) NC-a; (2) NC-b; (3) NC-c; (4 NC-d; (5) NC-e.
The above characterization showed that all the NC materials contained abundant surface functional groups. This mainly originated from the use of citric acid as the main carbon precursor. Meanwhile, the introduction of other kinds of organic compounds, such as biphenol, glycol or cyclohexylamine, as extra carbon sources influenced not only the pore structure but also the functional group properties of the NC materials. Compared with the other organic compounds, the use of the three isomers of biphenol as the extra carbon source led to the formation of quinone groups. The result suggested that the hydroxyl groups in biphenol were easily transformed into quinone groups during carbonization. The difference in structure of the three biphenol isomers also influenced the structure and surface chemistry of the NC materials. It should be mentioned here that the carbon yield of NC-a with $o$-dihydroxybenzene as the extra carbon source was rather low. This may be due to the fact that the close proximity of the two hydroxyl groups was not suitable for the formation of a long chain structure of the carbon precursor during the sol-gel and carbonization processes. The structural characteristics of NC-a, such as a low BET surface area and pore volume, may also be attributed to the structural feature of $o$-dihydroxybenzene.

Other organic compounds, such as ethylene diamine, tartaric acid and oxalic acid, were also used as the extra carbon source to prepare the NC materials. However, it is found that an obvious phase separation occurred during the heating process for the preparation of the precursor (the solid composite containing citric acid, organic compound, and aluminophosphate), which resulted in the formation of non-uniform carbon materials. These results clearly showed that the choice of the extra carbon source for the preparation of NC materials should be based on the physico-chemical properties of the organic compounds.

\subsection{Catalytic performance}

The various NC materials (including the NC-ref sample) were used to catalyze the aerobic oxidation of benzyl alcohol (Table 5). All the samples were active catalysts for the selective oxidation of benzyl alcohol to benzaldehyde. NC-e (prepared with cyclohexylamine) showed the highest activity (79.4\% conversion of benzyl alcohol after $12 \mathrm{~h}$ ), while NC-b and NC-c gave slightly lower conversions of benzyl alcohol (72.3\% and 74.2\%, respectively). These three samples were more active than the previously reported NC-ref catalyst (51.6\% conversion of benzyl alcohol after $12 \mathrm{~h}$ ) prepared with sucrose as the extra carbon source. These results showed that the use of cyclohexylamine, $m$-dihydroxybenzene or $p$-dihydroxybenzene as the extra carbon source further improved the catalytic performance of the NC materials. 
Table 5 Catalytic performance of the NC materials for the aerobic oxidation of benzyl alcohol

\begin{tabular}{lccc}
\hline Sample & \multicolumn{2}{c}{ Conversion of benzyl alcohol (\%) } & $\begin{array}{c}\text { Benzaldehyde } \\
\text { selectivity (\%) }\end{array}$ \\
\cline { 2 - 3 } & $6 \mathrm{~h}$ & $12 \mathrm{~h}$ & $>99$ \\
NC-a & 28.2 & 46.1 & $>99$ \\
NC-b & 48.5 & 72.3 & $>99$ \\
NC-C & 50.8 & 74.2 & $>99$ \\
NC-d & 19.2 & 35.0 & $>99$ \\
NC-e & 52.5 & 79.4 & $>99$ \\
NC-ref & 32.0 & 51.6 &
\end{tabular}

Reaction conditions: catalyst $0.3 \mathrm{~g}$, toluene $10 \mathrm{ml}$, benzyl alcohol 0.12 $\mathrm{ml}$ (1 mmol), $353 \mathrm{~K}, 1 \times 10^{5} \mathrm{~Pa}$.

Multiple aerobic oxidation cycles were carried out to examine the reusability of the NC catalysts. In these experiments, the catalyst was recovered after a cycle by simply decanting the reaction solution and drying at $373 \mathrm{~K}$ for some hours. The results showed that the catalyst lost some activity during the first three reaction cycles, and the conversion of benzyl alcohol was then maintained after four reaction cycles. These results suggested that part of the active sites on the surface of the NC materials were stable under the given reaction conditions, thus the samples can be recycled.

In our previous work, it was suggested that quinone groups on the surface of the NC-ref carbon material were the main active catalytic centers for the aerobic oxidation of benzyl alcohol [20]. Here, our present results suggested that some quinone groups also existed on the surface of various NC materials prepared from other carbon sources. This was the main reason why all the NC materials were active catalysts for the selective oxidation of benzyl alcohol. However, it is unexpected that NC-a, which has the highest concentration of quinone groups, exhibited a relatively low catalytic activity for the oxidation of benzyl alcohol, while NC-e, which possesses a relatively small amount of quinone groups, showed the highest catalytic activity. To explain this unusual result, we suggest that besides surface quinone groups, other functional groups such as acidic oxygen-containing groups (carboxyl and phenolic groups) [5] or nitrogen-containing groups $[39,40]$ also contribute to the catalytic oxidative activity. Other factors such as the structural parameters and surface polarity (originated from oxygen or nitrogen-containing groups) of the NC materials may also be important in the catalytic oxidation by affecting accessibility to the active centers or the transport rate of reagents [41].

\section{Conclusions}

A series of nanoporous carbon (NC) materials was prepared by directly carbonizing composites containing citric acid and aluminum phosphate with different organic compounds, biphenol, glycol, or cyclohexylamine, as the extra carbon source. The carbon source affected the structure and surface chemistry of the NC materials. The carbon materials were all active catalysts for the aerobic oxidation of benzyl alcohol to benzaldehyde. Surface quinone groups were the main active centers of the NC materials, and other oxygen-containing and nitrogen-containing groups also affected the catalytic performance. Further work is required to clarify the surface chemistry of the various NC materials, and to establish a clear relationship between the physico-chemical properties of the NC materials and their catalytic oxidation performance.

\section{References}

1 Joo S H, Choi S J, Oh I, Kwak J, Liu Z, Terasaki O, Ryoo R. Nature, 2001, 412: 169

2 Chai G S, Yoon B S, Yu J S, Choi J H, Sung Y E. J Phys Chem B, 2004, 108: 7074

3 Choi J Y, Hsu R S, Chen Z W. J Phys Chem C, 2010, 114: 8048

4 石国军, 赵䂆⿹, 黄玉安, 沈俭一. 催化学报 (Shi G J, Zhao Y, Huang Y A, Shen J Y. Chin J Catal), 2010, 31: 961

5 Dreyer D R, Jia H P, Bielawski C W. Angew Chem, Int Ed, 2010, 49: 6813

6 Zhang J, Liu X, Blume R, Zhang A, Schlogl R, Su D S. Science, 2008, 322: 73

7 唐水花, 孙公权, 齐静, 孙世国, 郭军松, 辛勤, Haarberg G M. 催化学报 (Tang Sh H, Sun G Q, Qi J, Sun Sh G, Guo J S, Xin Q, Haarherg G M. Chin J Catal), 2010, 31: 12

8 Du H D, Gan L, Li B H, Wu P, Qiu Y L, Kang F Y, Fu R W, Zeng Y Q. J Phys Chem C, 2007, 111: 2040

9 张强, 赵梦强, 黄佳琦, 骞伟中, 魏飞. 催化学报 (Zhang Q, Zhao M Q, Huang J Q, Qian W Zh, Wei F. Chin J Catal), 2008, 29: 1138

10 White R J, Budarin V, Luque R, Clark J H, Macquarrie D J. Chem Soc Rev, 2009, 38: 3401

11 Budarin V, Clark J H, Hardy J J E, Luque R, Milkowski K, Tavener S J, Wilson A J. Angew Chem, Int Ed, 2006, 45: 3782

12 Jaroniec M, Choma J, Gorka J, Zawislak A. Chem Mater, 2008, 20: 1069

13 Gierszal K P, Jaroniec M. J Am Chem Soc, 2006, 128: 10026

14 Shen W Z, Yang X P, Guo Q J, Liu Y H, Song Y R, Han Z X, Sun Q L, Cheng J. Mater Lett, 2006, 60: 3517

15 Bleda-Martínez M J, Lozano-Castelló D, Cazorla-Amorós D, Morallón E. Energy Fuels, 2010, 24: 3378

16 Titirici M M, Antonietti M, Baccile N. Green Chem, 2008, 10: 1204

17 Liu L, Wang F Y, Shao G S, Yuan Z Y. Carbon, 2010, 48: 2089

18 Lenghaus K, Qiao G G, Solomon D H, Gomez C, Rodriguez-Reinoso F, Sepulveda-Escribano A. Carbon, 2002, 40: 
743

19 Liu G, Liu Y, Wang Z L, Liao X Z, Wu S J, Zhang W X, Jia M J. Microporous Mesoporous Mater, 2008, 116: 439

20 Liu G, Liu Y, Zhang X Y, Yuan X L, Zhang M, Zhang W X, Jia M J. J Colloid Interf Sci, 2010, 342: 467

21 Zhao G M, Shi J H, Liu G, Liu Y, Wang Z L, Zhang W X, Jia M J. J Mol Catal A, 2010, 327: 32

22 Zu Y H, Liu G, Wang Z L, Shi J H, Zhang M, Zhang W X, Jia M J. Energy Fuels, 2010, 24: 3810

23 Boehm H P. Carbon, 1994, 32: 759

24 Sing K S W, Everett D H, Haul R A W, Moscou L, Pierotti R A, Rouquerol J, Siemieniewska T. Pure Appl Chem, 1985, 57: 603

25 Carati A, Ferraris G, Guidotti M, Moretti G, Psaro R, Rizzo C. Catal Today, 2003, 77: 315

26 Pang J, Li X, Wang D, Wu Z, John V T, Yang Z, Lu Y. $A d v$ Mater, 2004, 16: 884

27 Xia Y D, Mokaya R. Adv Mater, 2004, 16: 1553

28 Yang H, Yan Y, Liu Y, Zhang F, Zhang R, Meng Y, Meng Y, Li M, Xie S, Tu B, Zhao D. J Phys Chem B, 2004, 108: 17320

29 Su F, Zhao X S, Wang Y, Zeng J, Zhou Z, Lee J Y. J Phys Chem B, 2005, 109: 20200
30 Mawhinney D B, Yates J T. Carbon, 2001, 39: 1167

31 Liu Q S, Zheng T, Wang P, Guo L. Ind Crops Product, 2010, 31: 233

32 Zhou J H, Sui Z J, Zhu J, Li P, Chen D, Dai Y C, Yuan W K. Carbon, 2007, 45: 785

33 Biddinger E J, Ozkan U S. J Phys Chem C, 2010, 114: 15306

34 Pels J R, Kapteijn F, Moulijn J A, Zhu Q, Thomas K M. Carbon, 1995, 33: 1641

35 Kapteijn F, Moulijn J A, Matzner S, Boehm H P. Carbon, 1999, 37: 1143

36 Rosenthal D, Ruta M, Schlögl R, Kiwi-Minsker L. Carbon, 2010, 48: 1835

37 Xia W, Wang Y, Bergstrasser R, Kundu S, Muhler M. Appl Surf Sci, 2007, 254: 247

38 Kundu S, Wang Y M, Xia W, Muhler M. J Phys Chem C, 2008, 112: 16869

39 Yu H, Peng F, Tan J, Hu X W, Wang H J, Yang J, Zheng W X. Angew Chem, Int Ed, 2011, 50: 3978

40 Wang Y, Zhang J S, Wang X C, Antonietti M, Li H R. Angew Chem, Int Ed, 2010, 49: 3356

41 Fraga M A, Mendes M J, Jordao E. J Mol Catal A, 2002, 179: 243 